Article

\title{
Analysis of Different 100Cr6 Material States Using Particle-Oriented Peening
}

\author{
Anastasiya Toenjes ${ }^{1,2, * \mathbb{C}}$, Nicole Wielki ${ }^{1,2} \mathbb{C}$, Daniel Meyer ${ }^{1,2}(\mathbb{C})$ and Axel von Hehl ${ }^{1,2}$ \\ 1 University of Bremen and MAPEX Center for Materials and Processes, Bibliothekstraße 1, 28359 Bremen, \\ Germany; wielki@iwt-bremen.de (N.W.),dmeyer@iwt-bremen.de (D.M.), vonhehl@iwt-bremen.de (A.v.H.) \\ 2 Leibniz Institute for Materials Engineering-IWT, Badgasteiner Straße 3, 28359 Bremen, Germany \\ * Correspondence: toenjes@iwt-bremen.de; Tel.: +49-421-218-51491
}

Received: 24 August 2019; Accepted: 25 September 2019; Published: 28 September 2019

\begin{abstract}
As part of a novel method for evolutionary material development, particle-oriented peening is used in this work to characterize 100Cr6 (AISI 52100) microparticles that were heat-treated by means of a differential scanning calorimeter (DSC). The plastic deformation of the samples in particle-oriented peening is correlated with the microstructural properties considering different heat-treatment variations. While the heating rate was kept constant $(10 \mathrm{~K} / \mathrm{min})$ for all heat treatments, different heating temperatures $\left(500^{\circ} \mathrm{C}, 800^{\circ} \mathrm{C}, 1000^{\circ} \mathrm{C}\right.$ and $\left.1100{ }^{\circ} \mathrm{C}\right)$ were realized, held for $20 \mathrm{~min}$ and then cooled down at a rate of $50 \mathrm{~K} / \mathrm{min}$. Thereby, microstructural states with different (mechanical) properties are generated. For validation, microsections of the particles were analyzed and additional universal microhardness measurements (UMH) were performed. It could be shown that the quickly assessable plastic deformation descriptor reacts sensitively to the changes in the hardness due to the heat treatment.
\end{abstract}

Keywords: material development; characterization methods; high-throughput; calorimetry; descriptors; particle-oriented peening; plastic deformation

\section{Introduction and Approach}

The requirements placed on materials used in areas such as energy, mobility and health are becoming increasingly complex. Today, there are only a few high-throughput methods for characterizing materials and material states, such as nanoindentation tests from Zhao and Zhang [1-4]. In order to enable faster development of new construction materials to meet the rising demands of future components, a novel method has been established by the Collaborative Research Center 'Farbige Zustände' (CRC 1232) of the German Research Foundation (DFG). It focuses on the investigation of microparticles (diameter $\leq 1 \mathrm{~mm}$ ), which should allow conclusions to be drawn about the properties of components with conventional dimensions. For this purpose, quickly and easily determinable characteristics, so-called descriptors, are analyzed at different steps of a process chain. The microparticles can be generated utilizing droplet generators [5], which allow fast production of spherical droplets. Using a droplet generator, alloys can be varied quickly and several hundred samples can be generated per cycle in a reproducible way. This allows not only a finer variation of alloying elements, but also a significantly faster examination, since no conventional (large) samples have to be produced. In this way, optimal materials for specific applications can be identified. Through machine learning and heuristic methods, the experimental designs are adapted and the characterization process is continued until a novel material, with the required properties, is finally found $[6,7]$.

The properties of metallic materials do not only depend on the alloying elements but also on the modification of the material properties which occur throughout the process chain. The phases present in the microstructure and their special morphologies are also of great importance. In addition, the 
interactions of defects of the respective phases play a major role in many metallurgical processes. The microstructure can thus be influenced both by the heat-treatment and the transformation processes taking place, such as the dissolution and precipitation of phases or the change in the crystal structure, as well as by the alloying elements.

Using differential scanning calorimetry (DSC), heat-treatments can be performed, as well as characterization of structural changes, during a defined time-temperature program [8]. Thus, this method can be used among others for descriptor determination [9]. In this work, DSC was used for heat-treatment in a small furnace to achieve identical heat-treatment results for varied thermal conditions, for the small batches of microsamples. Heat flow curves allows precise determination of the austenitization temperature of the samples.

Particle-oriented peening was used to characterize the DSC heat-treated samples. Since the impact-induced plastic deformation of the single particles is related to the material-dependent deformation behavior, its analysis can be correlated to material properties such as hardness or deformation work. Characteristic measures of the deformed particles are used as descriptors that can be linked to material properties.

Due to its low test force and the locally limited measuring area, the instrumented universal microhardness measurement (UMH) allows the examination of the DSC-treated microparticles (after preparation of these). Thus, not only the Martens hardness but also the elastic and plastic shares of the deformation work, the elastic indentation modulus and the maximum indentation depth can be determined. Since these material-dependent quantities can be compared with the values determined using the particle-oriented peening process, the deformation behavior can be related to the microstructure-related material properties.

This work is aimed at showing that particle-oriented peening, is in principle, suitable for the evaluation of DSC heat-treated particles. Within the framework of CRC 1232, the peening is going to be used together with other methods to characterize the properties of spherical microparticles of different materials. This characterization then serves as an alternative assessment of material properties, which cannot be determined in a conventional way on the small samples.

\section{Materials and Methods}

\subsection{Materials}

The experiments were carried out with spherical microsamples (diameter $\mathrm{d}=0.8 \mathrm{~mm}$ ) of steel SAE 52100 (i.e., equivalent to $100 \mathrm{Cr} 6$ and AISI 52100). For the presented work, the commercially available samples were produced with a roller ball production process. This sample geometry was chosen in order to allow a comparison with the generated droplets of the future high-throughput process of the CRC 1232, and therefore, to enable the validation of short-term characterization by means of descriptors. The microstructure of the samples directly after the manufacturing process consists of martensite with retained austenite and globular carbides (Figure 1). 


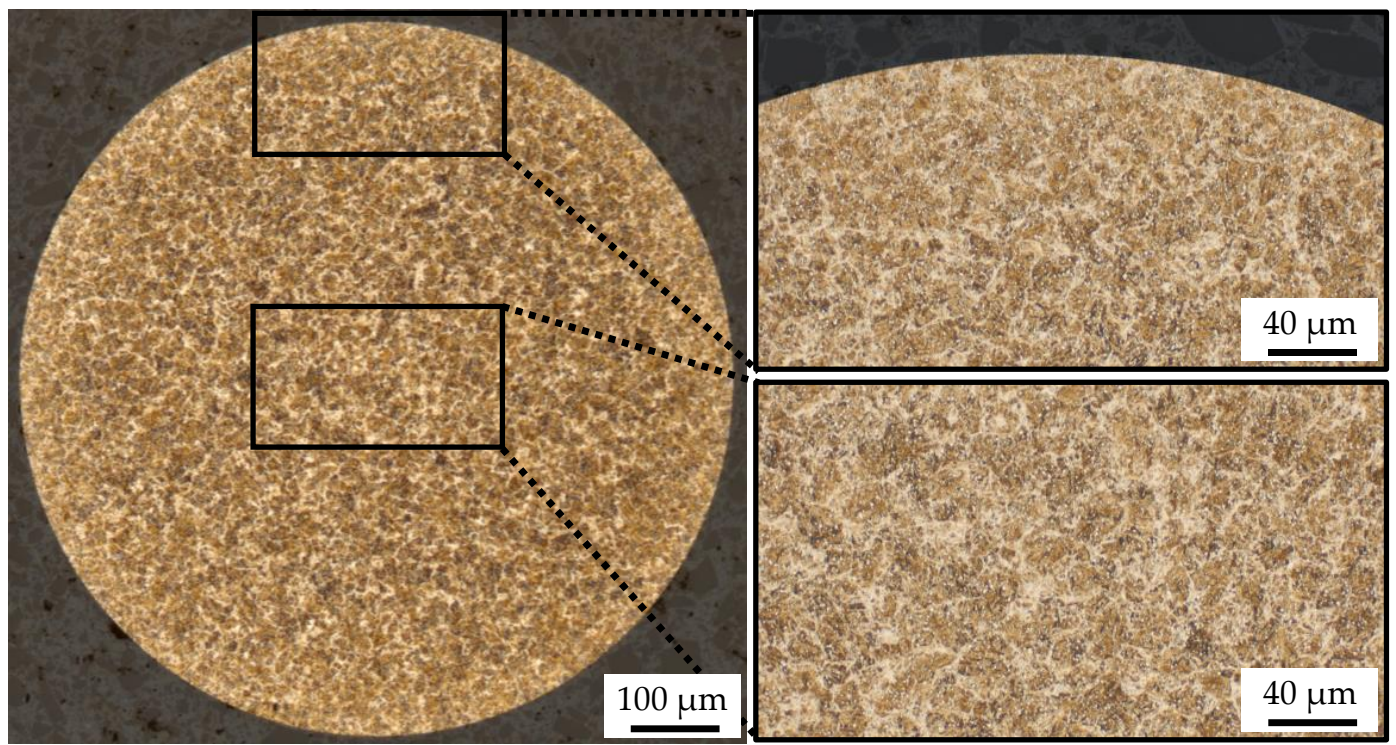

Figure 1. Microstructure of the microsamples after the roller ball production process; etched 25-30 s in $3 \%$ alcoholic $\mathrm{HNO}_{3}$, equatorial cut.

\subsection{Heat Treatment}

To vary the material properties prior to the particle-oriented peening step, the particles were heat-treated under varying conditions in advance. The experiments were performed in a differential scanning calorimeter because of the high precision of the furnaces, and to control the transformation points. The heat-treatments were carried out with a calorimeter of type HT TGA/DSC 3+ (C) METTLER TOLEDO, Hamburg, Germany). The samples were heated under an argon atmosphere at a rate of $10 \mathrm{~K} / \mathrm{min}$, to a temperature of $500^{\circ} \mathrm{C}, 800{ }^{\circ} \mathrm{C}, 1000^{\circ} \mathrm{C}$ and $1100^{\circ} \mathrm{C}$, then held at that temperature for $20 \mathrm{~min}$, before being cooled at a rate of $50 \mathrm{~K} / \mathrm{min}$, until they reached room temperature (Table 1).

Table 1. Heat treatments.

\begin{tabular}{ccccc}
\hline Designation & Heating Rate & Temperature & Holding Time & Cooling Rate \\
\hline $100 \mathrm{Cr} 6-500{ }^{\circ} \mathrm{C}$ & $10 \mathrm{~K} / \mathrm{min}$ & $500{ }^{\circ} \mathrm{C}$ & $20 \mathrm{~min}$ & $50 \mathrm{~K} / \mathrm{min}$ \\
$100 \mathrm{Cr} 6-800^{\circ} \mathrm{C}$ & $10 \mathrm{~K} / \mathrm{min}$ & $800^{\circ} \mathrm{C}$ & $20 \mathrm{~min}$ & $50 \mathrm{~K} / \mathrm{min}$ \\
$100 \mathrm{Cr} 6-1000^{\circ} \mathrm{C}$ & $10 \mathrm{~K} / \mathrm{min}$ & $1000^{\circ} \mathrm{C}$ & $20 \mathrm{~min}$ & $50 \mathrm{~K} / \mathrm{min}$ \\
$100 \mathrm{Cr} 6-1100{ }^{\circ} \mathrm{C}$ & $10 \mathrm{~K} / \mathrm{min}$ & $1100{ }^{\circ} \mathrm{C}$ & $20 \mathrm{~min}$ & $50 \mathrm{~K} / \mathrm{min}$ \\
\hline
\end{tabular}

\subsection{Universal Microhardness Measurements (UMH)}

In order to obtain information about the elastic and plastic deformation work, as well as the hardness of the particles, as a result of the DSC treatment, microhardness measurements were performed using a microhardness testing device (Fischerscope H100C, Helmut Fischer GmbH, Sindelfingen, Germany) with a Vickers indenter. Since the material properties influence the heat-treatment-dependent deformation behavior, values determined by the UMH are used for the validation of the results obtained by particle-oriented peening. For the investigations of the universal microhardness, the samples were prepared by embedding and grinding into the equatorial plane. The surface of the samples was fine-polished to achieve a low surface roughness of around $0.012 \mu \mathrm{m}$, so that microhardness measurements could be carried out. A maximum indentation force of $1000 \mathrm{mN}$ was used. The loading time, holding time and relief time were set to $10 \mathrm{~s}$ each. A total of 25 measurements were performed on each particle. 


\subsection{Particle-Oriented Peening}

As a process able to quickly deform a large number of particles in a highly defined and reproducible way, a newly established set-up for particle-oriented peening was used. At given peening conditions, the observed plastic deformation allows conclusions to be drawn about the mechanical properties of the samples. Thereby, single particles are accelerated with compressed air (jet pressure $p_{s}=4$ bar) to impact on a hardened contact plate (hardened 100Cr6; $60 \mathrm{HRC}$ ). The impact causes the particles to deform plastically according to their material properties. This plastic deformation is analyzed under a light microscope after the peening process, and the descriptor "linear plastic deformation" is determined. This is defined as the difference between the initial particle radius, $r$, and the distance from the center to the flattened surface after the impact (Figure 2). As shown for AlSi12 and X210Cr12 (AISI D3) in [10], Kämmler et al. examined that different mechanical properties, e.g., different hardness values, result in different descriptor values. It is, therefore, assumed that the different DSC heat-treatments also lead to distinguishable descriptor values.

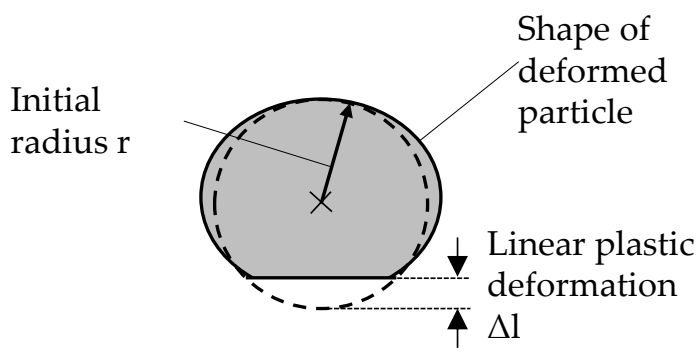

Figure 2. Definition of the determined linear plastic deformation (cf. [10]).

In addition to the plastic deformation, the impact force, F, of the particles approximated with the aid of a Kistler dynamometer, is also considered. As a result of previous calibration tests, a low-pass filter of $3000 \mathrm{~Hz}$, a sampling rate of 100,000 Hz and the time constant DC-long were used for the measurements. The impact force is defined as the difference between the maximum value determined and the basic value caused by the air flow of the jet pressure. Due to the short contact time and the limited possibility of the dynamometer used to record dynamic processes, the determined value does not represent the actual absolute force, but serves as an orientation value.

\section{Results}

\subsection{Heat-Treatment}

When heating the samples in the DSC, an endothermic peak with an onset temperature (austenitization temperature) of $751{ }^{\circ} \mathrm{C}$ and an end set temperature of $791{ }^{\circ} \mathrm{C}$ was measured. The exothermic transformation peak of the cooling curve had an onset at $731{ }^{\circ} \mathrm{C}$ and an end set at $628^{\circ} \mathrm{C}$. The maximum deviation of the evaluated temperatures was $1.2^{\circ} \mathrm{C}$. Figure $3 \mathrm{a}-\mathrm{d}$ shows the microstructure of the particles after the different heat-treatments near the surface and in the middle of the samples. The samples heat-treated at $500{ }^{\circ} \mathrm{C}$ have a homogeneous structure within the cross-sectional area of the sample. The microstructure consists of tempered martensite and carbides (Figure 3a). Despite the argon atmosphere, decarburization is obtained particularly near the surface of the samples heat-treated at $800{ }^{\circ} \mathrm{C}$. The microstructure of those samples thus consists of ferrite, a small amount of perlite, upper bainite and carbides (Figure 3b). After heat-treatment at $1000^{\circ} \mathrm{C}$, decarburization can also be observed near the surface of the samples. The microstructure consists of ferrite and a small amount of perlite (Figure 3c). The samples heat-treated at a temperature of $1100{ }^{\circ} \mathrm{C}$ mainly have a pearlitic structure with a small amount of ferrite and grain boundary carbides (Figure 3d). 
a) $\quad 500{ }^{\circ} \mathrm{C}$
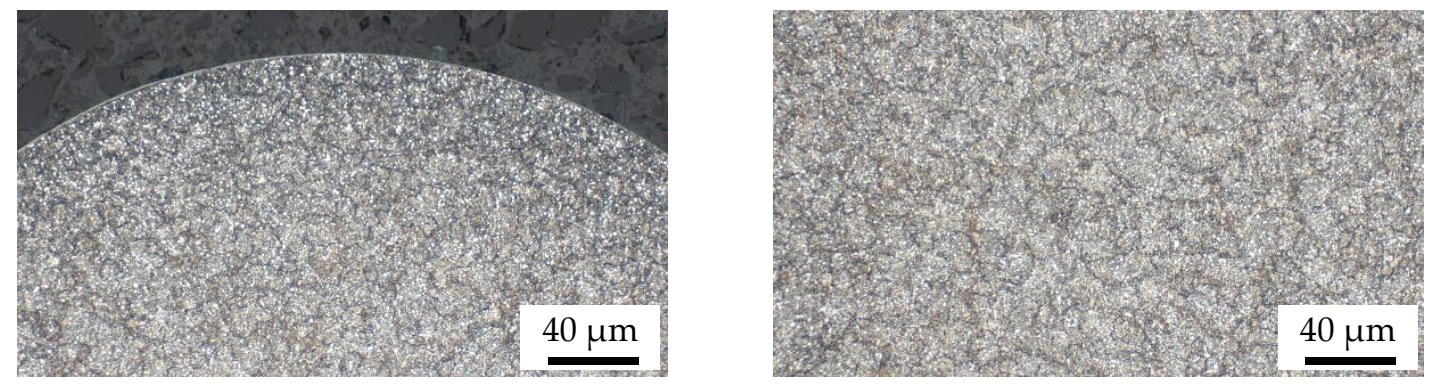

b) $\quad 800{ }^{\circ} \mathrm{C}$
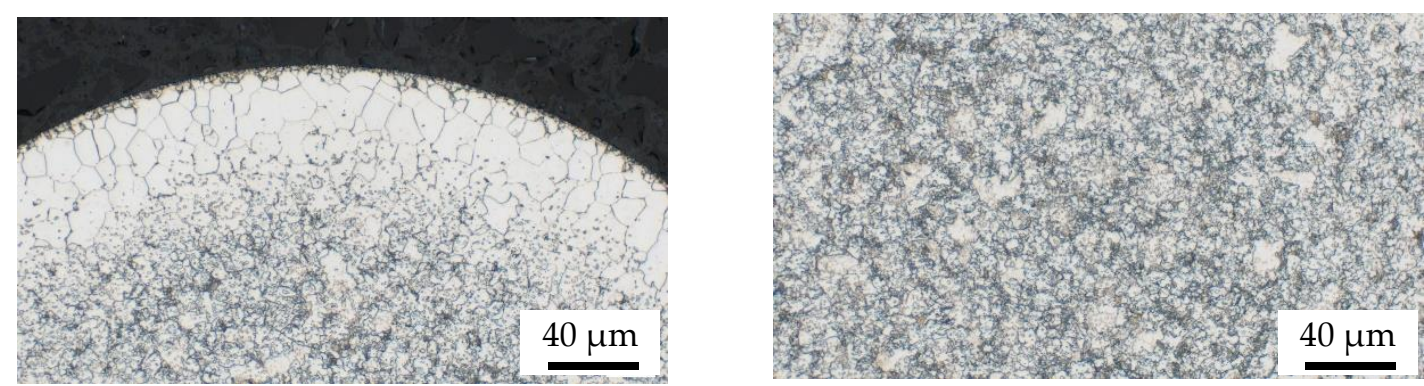

c) $\quad 1000{ }^{\circ} \mathrm{C}$
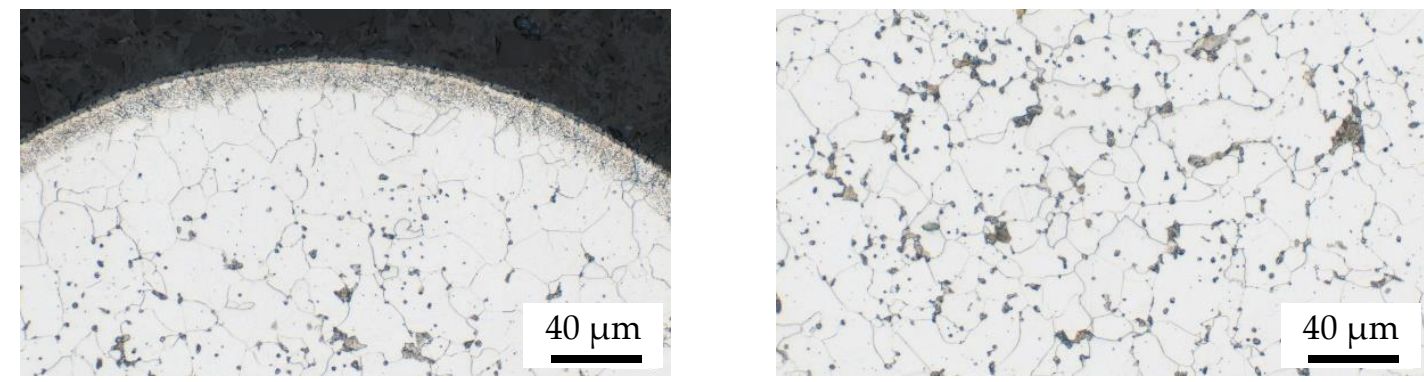

\section{d) $\quad 1100^{\circ} \mathrm{C}$}
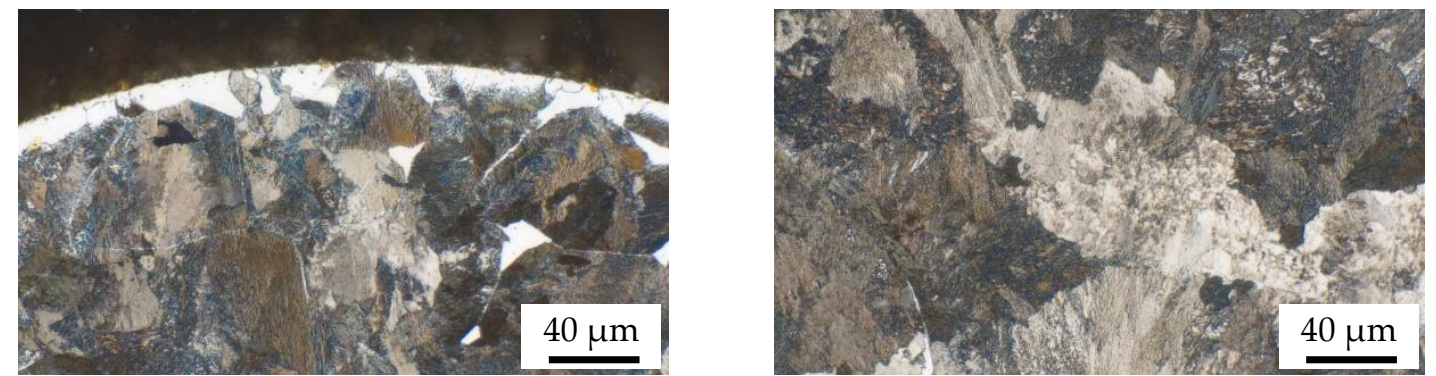

Figure 3. Microstructure of the microsamples near the surface (left) and in the middle of the sample (right) after the heat-treatment at (a) $500{ }^{\circ} \mathrm{C}$, (b) $800{ }^{\circ} \mathrm{C}$, (c) $1000{ }^{\circ} \mathrm{C}$ and (d) $1100{ }^{\circ} \mathrm{C}$; etched $25-30 \mathrm{~s}$ in $3 \%$ alcoholic $\mathrm{HNO}_{3}$, equatorial cut.

\subsection{Microhardness Measurement}

In order to corelate the descriptors obtained in particle-oriented peening, microhardness measurements were additionally performed. The elastic $\left(\mathrm{W}_{\mathrm{el}}\right)$ and plastic $\left(\mathrm{W}_{\mathrm{pl}}\right)$ shares of the deformation work, as well as the elastic indentation modulus, $\mathrm{E}_{\mathrm{IT}}$, are listed in Table 2 for the various heat-treatment states. Since the heating rate was kept constant $(10 \mathrm{~K} / \mathrm{min})$ for all heat-treatments, only the different heating temperatures $\left(500{ }^{\circ} \mathrm{C}, 800{ }^{\circ} \mathrm{C}, 1000{ }^{\circ} \mathrm{C}\right.$ and $\left.1100{ }^{\circ} \mathrm{C}\right)$ are listed. 
Table 2. Results of the performed microhardness measurements: values describing the deformation behavior measurements.

\begin{tabular}{ccccc}
\hline Designation & Heating Temperature & $\mathbf{W}_{\mathrm{el}}[\mu \mathrm{J}]$ & $\mathbf{W}_{\mathbf{p l}}[\boldsymbol{\mu J}]$ & $\mathbf{E}_{\mathrm{IT}}[\mathrm{GPa}]$ \\
\hline $100 \mathrm{Cr} 6-500{ }^{\circ} \mathrm{C}$ & $500^{\circ} \mathrm{C}$ & $0.184 \pm 0.001$ & $0.860 \pm 0.008$ & $230 \pm 4$ \\
$100 \mathrm{Cr} 6-800{ }^{\circ} \mathrm{C}$ & $800^{\circ} \mathrm{C}$ & $0.150 \pm 0.003$ & $1.316 \pm 0.026$ & $189 \pm 2$ \\
$100 \mathrm{Cr} 6-1000{ }^{\circ} \mathrm{C}$ & $1000^{\circ} \mathrm{C}$ & $0.125 \pm 0.008$ & $1.466 \pm 0.023$ & $207 \pm 15$ \\
$100 \mathrm{Cr} 6-1100{ }^{\circ} \mathrm{C}$ & $1100^{\circ} \mathrm{C}$ & $0.167 \pm 0.007$ & $1.022 \pm 0.069$ & $218 \pm 3$ \\
\hline
\end{tabular}

The tempered martensite present for the state heat-treated at $500{ }^{\circ} \mathrm{C}$ has the highest elastic deformation work and the highest elastic indentation modulus. The plastic deformation work is correspondingly the lowest in comparison to the considered heat-treatment states. This is similar for the mainly pearlitic microstructure, which is present in the particles heat-treated at $1100{ }^{\circ} \mathrm{C}$. Here, too, the elastic part of the deformation work, as well as the elastic indentation work, are higher and the plastic part of the deformation work is lower than in the case of the particles that have been heat-treated at $800{ }^{\circ} \mathrm{C}$ and $1000{ }^{\circ} \mathrm{C}$. With the help of microhardness measurements, the Martens hardness of the individual DSC states could also be determined. As shown in Figure 4a, the heat-treatment with the lowest heating temperature is associated with the highest hardness. When the heating temperature drops, the hardness decreases first, before a higher value is visible again at $1100{ }^{\circ} \mathrm{C}$. The maximum penetration depth, which was also determined, behaves contrary to the hardness (Figure $4 \mathrm{~b}$ ). The higher the measured hardness, the lower the maximum penetration depth is.
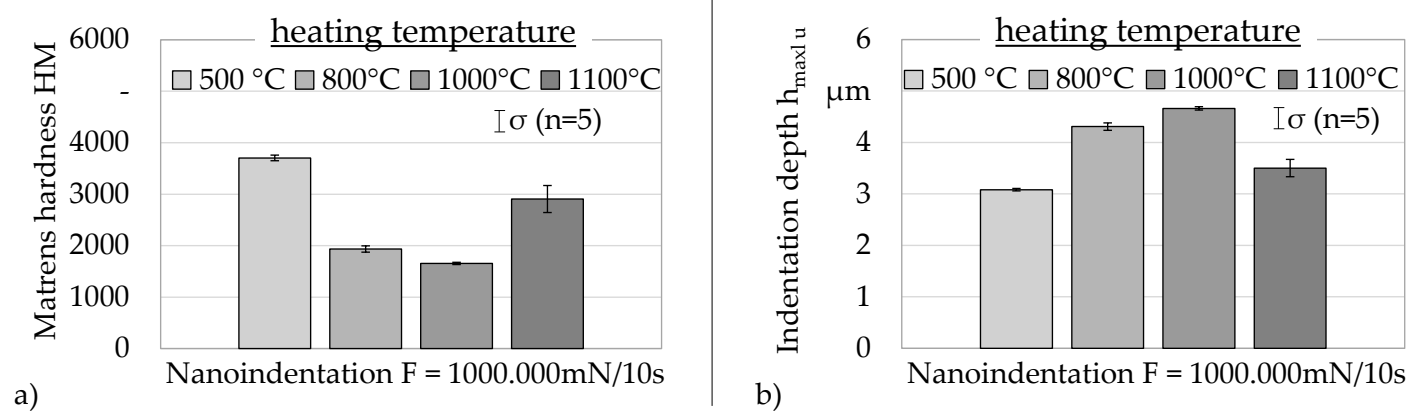

Figure 4. Exemplary results of microhardness measurement (a) indentation depth, (b) Martens hardness.

\subsection{Particle-Oriented Peening}

While the plastic deformation obtained investigating the different DSC-treated particles varies significantly when a constant jet pressure of $\mathrm{p}_{\mathrm{s}}=4 \mathrm{bar}$ is applied, the approximated impact force shows no significant variation, and confirms that particles of the same size have the same amount of kinetic energy when striking the contact plate. Average values (out of 10 measurements) obtained for the descriptor "linear plastic deformation" (a) and "impact force" (b) are shown in Figure 5. The error bars visualize the standard deviation calculated. Analyzing Figure 5, the following conclusions can be drawn:

- Up to a heating temperature of $1000{ }^{\circ} \mathrm{C}$, an increase in heating temperature results in an increasing linear plastic deformation.

- At heating temperatures above $1000^{\circ} \mathrm{C}\left(\mathrm{cf} .1100^{\circ} \mathrm{C}\right.$ ), a decrease of the linear plastic deformation can be observed.

Considering the findings from Figure 5a, the linear plastic deformation of the particles shows an opposite trend to that of the hardness values. This indicates the direct correlation between the quickly assessable plastic deformation in particle-oriented peening and material properties varied in a defined way by DSC. 


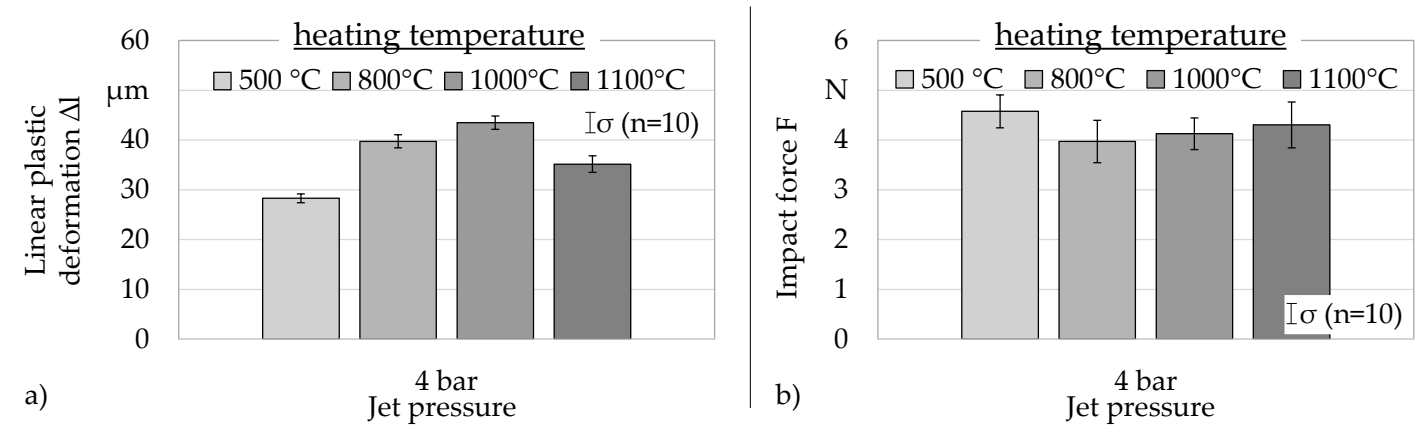

Figure 5. Descriptor values obtained after particle-oriented peening of DSC-treated particles (a) linear plastic deformation, (b) approximated impact force.

\section{Discussion}

The temperature curves recorded during the DSC show that a complete austenitization has only occurred at a maximum temperature of $1100^{\circ} \mathrm{C}$. Thus, a completely new microstructure was formed, resulting in a higher hardness caused by this maximum temperature. Lower heating temperatures mainly result in tempering of the previously martensitic microstructure. Since $500^{\circ} \mathrm{C}$ is a comparatively low temperature for tempering, the hardness here is still high due to the remaining martensite. Since a higher hardness results in a greater resistance to deformation, both linear plastic deformation and the maximum penetration depth determined in UMH have the lowest values for material states of high hardness. The deformation work determined coincides with these observations, since a comparatively large elastic and comparatively small plastic part was determined during the heat-treatment at $500{ }^{\circ} \mathrm{C}$. Increasing the heating temperature to $800^{\circ} \mathrm{C}$ resulted in the material being in a two-phase region for the duration of the holding time. For this reason, decarburization has occurred near the surface of the particles, which explains the mixed structure of ferrite, perlite, upper bainite and carbides. Since the particle-oriented peening mainly causes a deformation of the particle surface and subsurface area, the observed microstructural effects in the outer surface and subsurface layers (decarbonized) may affect the correlation between the plastic deformation after peening and the hardness measured in the center of the particles. However, this would only be an issue if other heat-treatments were used and caused different effects in the outer layers of the particles. Nevertheless, the development of the obtained descriptors, with changing hardness, is represented correctly. At a heating temperature of $1000{ }^{\circ} \mathrm{C}$, the austenitization temperature is already exceeded. However, this temperature, in combination with the holding time, is not sufficient for a complete phase transformation. Thus, a mixed microstructure with ferrite and a small amount of perlite still results. Since decarburization is less pronounced, the microstructure is more homogeneous.

As the mass of the particles is constant for all heat-treatments, and the jet pressure is kept constant as well, no significant variations of the impact force were expected. However, due to slight variations of the volume occupied by different phases, a minimal variation of the diameter of the particles can occur. This might influence the acceleration by the jet stream and be an explanation for the very small observed variations of the impact force. The fact that there are comparable standard deviations for all DSC conditions, shows that a comparison of the results is possible due to matching particle sizes.

\section{Conclusions and Outlook}

In this publication, hardened 100Cr6 particles underwent different DSC heat-treatments to vary the microstructural and mechanical properties of the metal in a defined way. The influence of the different heat-treatments on the deformation behavior of the particles was investigated using particle-oriented peening. The descriptors were correlated to material properties using micrographs and microhardness measurements. It could be shown that the linear plastic deformation descriptor reacts sensitively to the altered hardness of the particles due to heat-treatment. According to the Martens hardness and the 
degree of elastic and plastic deformation determined in the $\mathrm{UMH}$, the linear plastic deformation clearly increases with decreasing hardness (from a heating temperature of $500^{\circ} \mathrm{C}$ to $1000{ }^{\circ} \mathrm{C}$ ). The increased hardness of the particles heat-treated at $1100^{\circ} \mathrm{C}$ leads to lower values of linear plastic deformation and penetration depth. There are similarities in the order of magnitude to the values determined at $500{ }^{\circ} \mathrm{C}$.

In addition to $100 \mathrm{Cr} 6$, other alloy compositions will be considered for subsequent investigations. Furthermore, it will be analyzed if and how the sample generation process affects the observed results in a quantitative way. Here, commercially available roller ball particles were used. It is of great interest how they compare to particles generated in a single drop generator. The investigation of these "dropped" particles represents the basis of the CRC hypothesis.

Author Contributions: A.T. performed the DSC experiments and wrote the paper by the aid of N.W., who performed the particle peening experiments. D.M and A.v.H. supervised all investigations and supported with their expert knowledge. The CRC 1232 'Farbige Zustände' contributed the investigated materials.

Funding: This research was funded by the German Research Foundation (DFG).

Acknowledgments: Financial support of subprojects U03 “Thermal and thermomechanical heat-treatment" and U04 "Mechanical Treatment" of the Collaborative Research Center CRC 1232 by the Deutsche Forschungsgemeinschaft (DFG, German Research Foundation)—project number 276397488—SFB 1232 is gratefully acknowledged.

Conflicts of Interest: The authors declare no conflict of interest.

\section{References}

1. Zhao, J.C. The diffusion-multiple approach to designing alloys. Annu. Rev. Mater. Res. 2005, 35, 51-73. [CrossRef]

2. Zhang, Q.F.; Zhao, J.C. Extracting interdiffusion coefficients from binary diffusion couples using traditional methods and a Forward-Simulation method. Intermetallics 2013, 37, 132-141. [CrossRef]

3. Zhao, J. Combinatorial approaches as effective tools in the study of phase diagrams and Composition-Structure-Property relationships. Prog. Mater. Sci. 2006, 51, 557-631. [CrossRef]

4. Zhao, J.C.; Zheng, X.A.; Cahill, D.G. High-Throughput measurements of materials properties. JOM 2011, 63, 40-44. [CrossRef]

5. Ellendt, N.; Ciftci, N.; Goodreau, C.; Uhlenwinkel, V.; Mädler, L. Solidification of single droplets under combined cooling conditions. IOP Conf. Ser. Mater. Sci. Eng. 2016, 117, 12057. [CrossRef]

6. Drechsler, R.; Eggersglüß, S.; Ellendt, N.; Huhn, S.; Mädler, L. Exploring Superior Structural Materials Using Multi-Objective Optimization and Formal Techniques. In Proceedings of the 6th IEEE International Symposium on Embedded Computing and System Design, Patna, India, 15-17 December 2016.

7. Ellendt, N.; Mädler, L. High-Throughput Exploration of Evolutionary Structural Materials. HTM J. Heat Treat. Mater. 2018, 73, 3-12. [CrossRef]

8. Morra, P.V.; Böttger, A.J.; Mittemeijer, E.J. Decomposition of Iron-Based Martensite. A kinetic analysis by means of differential scanning calorimetry and dilatometry. J. Therm. Anal. Calorim. 2001, 64, 905-914.

9. Toenjes, A.; Sonnenberg, H.; Plump, C.; Drechsler, R.; von Hehl, A. Measurement and Evaluation of Calorimetric Descriptors for the Suitability for Evolutionary High-Throughput Material Development. Metals 2019, 9, 149. [CrossRef]

10. Kämmler, J.; Wielki, N.; Guba, N.; Ellendt, N.; Meyer, D. Shot peening using spherical micro specimens generated in High-Throughput processes. Mater. Werkst. 2019, 50, 5-13. [CrossRef] 